\title{
Phytofabrication of bioinduced silver nanoparticles for biomedical applications
}

\author{
This article was published in the following Dove Press journal: \\ International Journal of Nanomedicine \\ 12 November 2015 \\ Number of times this article has been viewed
}

\section{Nabeel Ahmad' \\ Sharad Bhatnagar' \\ Syed Salman Ali \\ Rajiv Dutta ${ }^{3}$}

'School of Biotechnology, ${ }^{2}$ School of Pharmaceutical Sciences, IFTM University, Lodhipur Rajput, Moradabad, Uttar Pradesh, India; ${ }^{3}$ Institute of Bio-Science and Technology, Shri Ramswaroop Memorial University, Barabanki, Uttar Pradesh, India
Correspondence: Rajiv Dutta Institute of Bio-Science and Technology, Shri Ramswaroop Memorial University, Village-Hadauri, Post-Tindola, Lucknow Deva Road, Barabanki 225003,

Uttar Pradesh, India

Tel +9l 9839236821

Email director.sbt@gmail.com
Abstract: Synthesis of nanomaterials holds infinite possibilities as nanotechnology is revolutionizing the field of medicine by its myriad applications. Green synthesis of nanoparticles has become the need of the hour because of its eco-friendly, nontoxic, and economic nature. In this study, leaf extract of Rosa damascena was used as a bioreductant to reduce silver nitrate, leading to synthesis of silver nanoparticles (AgNPs) in a single step, without the use of any additional reducing or capping agents. The synthesized nanoparticles were characterized by the use of UV-visible spectroscopy, fourier transform infrared spectroscopy, dynamic light scattering, transmission electron microscopy, and field emission scanning electron microscopy. Time-dependent synthesis of AgNPs was studied spectrophotometrically. Synthesized AgNPs were found to possess flower-like spherical structure where individual nanoparticles were of $16 \mathrm{~nm}$ in diameter, whereas the agglomerated AgNPs were in the range of 60-80 nm. These biologically synthesized AgNPs exhibited significant antibacterial activity against Gram-negative bacterial species but not against Gram-positive ones (Escherichia coli and Bacillus cereus). Anti-inflammatory and analgesic activities were studied on a Wistar rat model to gauge the impact of AgNPs for a probable role in these applications. AgNPs tested positive for both these activities, although the potency was less as compared to the standard drugs.

Keywords: silver nanoparticles, green synthesis, anti-inflammatory, analgesic, animal model study, antibacterial

\section{Introduction}

Nanobiotechnology is an interdisciplinary field traversing both nanotechnology and biological sciences, concerning the utilization of biological systems to fabricate functional nanoscale architectures comprising of organic and inorganic materials. This technical approach to biology has allowed scientists to imagine and create systems that can be used to study the cell as a biological molecular machine at the nanoscale level. ${ }^{1-3}$

Biological systems often feature natural, functional nanomaterials, eg, butterfly wing scale, natural colloids (milk), horny material (skin, claws, beaks, hair, and feather), and even our bone matrix. This provides credence to the fact that nature is absolutely capable of fabrication of nanoparticles and nanomaterials on its own and that this particular aspect can be harnessed by the researchers to overcome the drawbacks associated with chemical synthesis of nanoparticles. This use of biological entities to create nanoparticles has been designated as "green synthesis" and is considered to be far more beneficial since it is economical, eco-friendly, and applicable for large-scale synthesis as it operates on low pressure, less input of energy, and low temperatures. The lack of toxic byproducts and consequent decrease in degradation of the product renders this technique more preferable over physical and classical chemical methods. 
The variety in the plant species having reduction properties to produce nanoparticles makes them an ideal candidate for fabrication since the milieu present for synthesis determines the morphology, properties of nanoparticles, and owing to the differences in reducing capacities, capping properties, stabilizing properties among various species; plants provide an excellent platform for the control of these properties. The relatively higher stability of nanoparticles produced by plant sources as compared to microbial ones further tip the scales in favor of synthesis utilizing plant sources. Various plants can be employed for the nanoparticle synthesis such as Cinnamomum camphora, Medicago sativa, Pelargonium graveolens, Avena sativa, Azadirachta indica, Tamarindus indica, Emblica officinalis, Aloe vera, Coriandrum sativum, Carica papaya, Parthenium hysterophorus, Acanthella elongata, Sesuvium portulacastrum, Chrysanthemum indicum L, Melia azedarach L, Saraca indica, Caesalpinia coriaria, Vitex negundo L..$^{425}$ Biomolecules like honey can also be used for the synthesis of gold nanoparticles. ${ }^{26,27}$ A variety of nanoparticles exhibiting numerous shapes such as spherical, octahedral, nanoprisms, tetrahedral, suboctahedral, irregular shaped, nanotriangles, decahedral multiple twinned, icosahedral multiple twinned, hexagonal platelets, nanorods, etc, with sizes varying from 1 to $100 \mathrm{~nm}$ have been produced by exploiting plant sources..$^{28,29}$ Because of their submicroscopic size and unique material characteristics, manufactured nanoparticles may find practical applications in a variety of areas including medicine, engineering, catalysis, and in bioelectronics. ${ }^{30,31}$

Physical and chemical properties of materials at the nanoscale level are radically transformed because of high surface area to volume ratio. Owing to this, nanomaterials possess high catalytic activity while various bulk materials lack these properties.

Silver nanoparticles (AgNPs) have tremendous potential applications in radically different fields ranging from textiles to water purification and from electronics and cosmetics to medicine because of their unique physical, chemical, and biological properties. AgNPs are well known to possess inhibitory and bactericidal properties which might provide a solution to the increasing trend of antibiotic resistance exhibited by pathogenic bacteria that has materialized in recent years. ${ }^{32,33}$ This is an area where AgNPs might prove to be exceptionally valuable to the medical community. Nanoparticles have been proven to be a valuable ally in the fight against several diseases. Gold nanoparticles used against various cancers have often resulted in positive effects by decreasing the chemoresistance of the tumor. ${ }^{34-36} \mathrm{AgNPs}$ have been implicated in induction of apoptosis in neutrophils and inhibition of de novo protein synthesis. ${ }^{37}$ Moreover, they are increasingly being used in antimicrobial agents for augmentation of their potencies. ${ }^{23-25,38,39} \mathrm{AgNPs}$ are widely being used and examined in areas such as biosensing, photonics (as spectrally selective coatings for solar energy absorption), electronics (as an intercalation material for electrical batteries), antimicrobial application, and are also used as potential optical receptors for biolabeling. ${ }^{40-42}$

The main aim of this study was to synthesize AgNPs using aqueous leaves extract of Rosa damascena as bioreducing agent to reduce $\mathrm{Ag}^{+}$to $\mathrm{Ag}^{0}$, which were later analyzed and characterized by using ultraviolet-visible (UV-Vis) spectroscopy, fourier transform infrared spectroscopy (FTIR), transmission electron microscopy (TEM), dynamic light scattering (DLS), and field emission scanning electron microscopy (FESEM). After characterization, the in vitro antimicrobial, anti-inflammatory, and analgesic activities of the green synthesized AgNPs were evaluated.

\section{Materials and methods Chemicals and reagents}

All the chemicals used, including silver nitrate $\left(\mathrm{AgNO}_{3}\right)$, were procured from Sigma-Aldrich Co., (St Louis, MO, USA) and were of high grade analytical quality. Deionized water was used for the entire duration of the experiments. Fresh and healthy leaves of $R$. damascena were harvested from School of Biotechnology, IFTM University, Moradabad, Uttar Pradesh, India.

\section{Biogenesis of AgNPs: preparation of plant leaf extract}

Healthy leaves of $R$. damascena were washed twice with distilled water, cut into fine pieces, and dried in a hot air oven at $60^{\circ} \mathrm{C}$ for 4 hours. Dried leaves were grounded using mortar and pestle to obtain a fine powder. Ten grams of sterilized leaf powder was added in $100 \mathrm{~mL}$ distilled water and boiled for 30 minutes in a water bath at $100^{\circ} \mathrm{C}$. This mixture was cooled to room temperature and then filtered using Whatman filter paper. This filtered leaf extract was stored at $-30^{\circ} \mathrm{C}$ till further use and has been used as obtained in all the experiments unless stated otherwise.

\section{Biosynthesis of AgNPs}

AgNPs were synthesized according to the procedure described in our previous study. ${ }^{43}$ The aqueous solution of $1 \mathrm{mM} \mathrm{AgNO}$ was prepared and used for the synthesis of AgNPs. Approximately $10 \mathrm{~mL}$ of $R$. damascena extract was added to $90 \mathrm{~mL}$ aqueous solution of $1 \mathrm{mM} \mathrm{AgNO}_{3}$ for reduction into $\mathrm{Ag}^{0}$ ions and was incubated for a period of 
15 minutes with vigorous stirring using magnetic stirrer at room temperature. A rapid change in color was observed indicating the initiation of the generation of AgNPs. The resultant mixture of AgNPs and extract obtained after the synthesis was kept under mild stirring conditions for 24 hours. The obtained mixture was then purified by centrifugation at $10,000 \mathrm{rpm}$ for 15 minutes, and this was followed by dispersion of the pellet in deionized water.

\section{Characterization of AgNPs}

The synthesized AgNPs, and the effect of the extract on the synthesis were characterized by UV-Vis spectroscopy, FTIR, DLS, TEM, and FESEM.

\section{UV-Vis spectrophotometric analysis}

UV-Vis spectra of the samples were analyzed by PerkinElmer $\mathrm{UV}-\mathrm{V}$ is double beam spectrophotometer. The scanning range for the samples was 300-600 nm, operated at a resolution of $1 \mathrm{~nm}$. Deionized water was used as blank.

\section{FTIR spectroscopy}

FTIR spectrum of AgNPs and leaf extract was recorded using PerkinElmer Spectrum BX, FT-IR (PerkinElmer, Akron, $\mathrm{OH}, \mathrm{USA}$ ) at room temperature through potassium bromide pellet method. NPs was dispersed into $\mathrm{KBr}$ matrix, mixed well, and pelletized. The pellet was kept in IR path and spectrum was measured in the $400-4,000 \mathrm{~cm}^{-1}$ range. FTIR spectroscopy measurements were carried out to recognize the biogroups that are attached on the surface of AgNPs from the leaf extract used for the synthesis.

\section{Transmission electron microscopy analysis}

The morphology and particle size of synthesized AgNPs were determined by TEM using a Hitachi Model H-7500 (Hitachi Ltd., Tokyo, Japan) with an acceleration voltage of $200 \mathrm{kV}$.

\section{Dynamic light scattering spectroscopy}

The size distribution of AgNPs was carried out by DLS spectrophotometer (DynaPro-TC-04; Protein Solutions, Santa Barbara, CA, USA) equipped with a temperaturecontrolled microsampler. The mean hydrodynamic radius $\left(R_{\mathrm{h}}\right)$ was measured by using the Stokes-Einstein equation:

$$
R_{\mathrm{h}}=k T / 6 \pi \eta D
$$

where $R_{\mathrm{h}}$ is the hydrodynamic radius, $k$ is Boltzmann's constant, $T$ is absolute temperature, $\eta$ is the viscosity of solvent, and $D$ is translational diffusion coefficient.

\section{Field emission scanning electron microscopy}

The surface morphology of AgNPs was determined by FESEM, JEOL JSM 6700F (JEOL, Tokyo, Japan).

\section{Effect of temperature on AgNPs synthesis}

The effect of temperature on the rate of synthesis of AgNPs was studied by adding $90 \mathrm{~mL}$ of $1 \mathrm{mM} \mathrm{AgNO}_{3}$ solution to $10 \mathrm{~mL} R$. damascena leaf extract and carrying out the biosynthesis at different temperatures, viz, $10^{\circ} \mathrm{C}, 20^{\circ} \mathrm{C}, 30^{\circ} \mathrm{C}$, $40^{\circ} \mathrm{C}$, and $50^{\circ} \mathrm{C}$ for up to 6 hours. The formation of AgNPs was observed by their color change and further validated spectrophotometrically.

\section{Test for phenolic compounds}

Ferric ion reduction test was performed to identify the presence of phenolic compounds in $R$. damascena leaf extract. In this test, $\mathrm{FeCl}_{3}$ solution $(30 \mathrm{mM})$ was added to plain $R$. damascena leaf extract solution and to the supernatant left behind after the synthesis of AgNPs. The color change of the leaf extract was observed to detect the presence of phenolic compounds. Hydrolysable tannins give blue black color initially and later condense exhibiting brownish green color with precipitation as a consequence of formation of ferrous compounds. ${ }^{44}$

\section{Screening for antibacterial properties}

The synthesized nanoparticles were studied for their antibacterial action against the Gram-positive and Gram-negative bacteria. Escherichia coli (Gram-negative) and Bacillus cereus (Gram-positive) were used as the targets in the bactericidal assay. The cultures were cultivated in broth for 24 hours before inoculation on the assay plate. Three wells of $7 \mathrm{~mm}$ diameter were prepared on Mueller Hinton agar plate with the use of gel puncture. The cultures were inoculated onto the assay media with a sterile cotton swab. Leaf extract was added to the first well to act as a control, penicillin was added to the second and $25 \mu \mathrm{L}$ of synthesized particles was inoculated to the third well. The plates were incubated for $37^{\circ} \mathrm{C}$ for 24 hours; the zones of inhibition were observed.

\section{Test for anti-inflammatory properties of AgNPs on rat model}

In vivo study: experimental animals and conditions Wistar albino rats (150-200 g) were selected, housed in polypropylene cages in an air conditioned area at $23^{\circ} \mathrm{C} \pm 2{ }^{\circ} \mathrm{C}$, $50 \%-60 \%$ relative humidity with 10 hours/ 14 hours light and dark cycle, and allowed to acclimatize for 14 days before tests. Animals were allowed free access to slandered dry pellet diet 
and given water ad libitum. Animals were kept in plastic rat cages throughout the entire experiment; food was not given to the animals 12 hours before drug administration study. The litter in the cages was renewed thrice a week to ensure hygiene and maximum comfort for animals. The Institutional Animal Ethical Committee (IAEC) at IFTM University, Moradabad, Uttar Pradesh, India (Protocol approval number 2012/837/ $\mathrm{AC} / \mathrm{PhD} / 05)$ approved the protocol for this study.

The experimental animals were divided into three groups with six animals each.

\section{Carrageenan-induced paw edema method}

For the carrageenan-induced paw edema study, the groups were treated as following:

1) Group 1 served as control.

2) Group 2 served as standard - treated with $10 \mathrm{mg} / \mathrm{kg}$ of indomethacin orally.

3) Group 3 served as test group - treated with AgNPs colloidal suspension $0.3 \mathrm{mg} / \mathrm{kg}$ body weight orally.

\section{Procedure}

Anti-inflammatory activity was studied in three groups of six rats each. The AgNP colloidal suspension was orally administered daily for 4 days prior to injection of carrageenan. Edema was induced according to the method described by Patil et al. ${ }^{45}$ Briefly, $0.1 \mathrm{~mL}$ of $1 \%$ carrageenan in sterile saline was injected into one hind paw under the plantar aponeurosis. A similar volume of saline solution was injected into the other hind paw. The paw volume was measured before injection of carrageenan or saline by the digital plethysmograph, and the time course of edema formation was followed over 3 hours. In separate groups of animals, indomethacin $10 \mathrm{mg} / \mathrm{kg}$ of body weight was administered orally as standard drug and $1 \%$ carboxymethyl cellulose solution as solvent control. A fixed amount of AgNPs $0.3 \mathrm{mg} / \mathrm{kg}$ body weight $(0.19 \mathrm{mg} / \mathrm{mL})$ was administered orally 30 minutes before carrageenan injection. The dosage was decided on the basis of previously studied literature. ${ }^{46}$ The volume increase of the inflamed paw was estimated by subtracting the volume of the contralateral paw. The anti-inflammatory effect of the drugs was evaluated as the degree of edema inhibition. ${ }^{47}$

\section{Evaluation parameters}

Percentage inhibition in edema was calculated using the formula:

$$
\% A=\frac{\% I_{c}-I_{e}}{I_{c}} \times 100
$$

where $\% I_{c}$ and $I_{e}$ are the mean inflammation values reached in control and experimental groups. Inhibition in edema represents the inhibition of the inflammation. Edema was determined by measuring the paw volume using a digital plethysmometer.

\section{Test for analgesic activity on rats: radiant heat tail-flick model}

Radiant heat tail-flick model in rats was employed to establish the central analgesic activity. ${ }^{48}$ This was achieved by studying and measuring changes in the sensitivity of the prescreened rats (the intensity of the light being experimentally defined such that animals withdrew their tails within 2-4 seconds) to heat stress applied to their tails, after introducing the drugs into their system. Tail-flick latency was assessed by the analgesiometer. All the drugs were provided orally to the respective group of rats. The current delivered through the nichrome wire, acting as the heat source, was maintained steadily at $5 \mathrm{~A}$. The standard pentazocine dosage was kept at $30 \mathrm{mg} / \mathrm{kg}$, whereas AgNPs were administered at a dose of $0.025 \mathrm{mg} / \mathrm{mL}$. The gap amid the heat source (nichrome wire) and the tail was kept constant at $1.5 \mathrm{~cm}$, with the application site of the heat on the tail being maintained within $2 \mathrm{~cm}$ from the base of the tail. The cutoff reaction time was set to +10 seconds to avoid any tissue injury during the process. Tail-flick latency was considered from +30 minutes after the drug administration.

\section{Evaluation}

The time taken by rats to withdraw (flick) the tail was taken as the reaction time. The animals were subjected to the same test procedure at $+30,+60,+120$, and +180 minutes after the administration of test/standard/control drug.

\section{Statistical analysis}

All data were expressed as mean \pm standard error of mean $(n=6)$ and analyzed using one way analysis of variance (ANOVA) followed by Dunnett's test.

\section{Results \\ Biosynthesis of AgNPs}

AgNPs appear dark reddish brown in color in aqueous solution due to excitation of surface plasmon resonance, which is a signature feature of AgNPs. When the extract was added to the aqueous solution of $\mathrm{AgNO}_{3}$ under vigorous stirring by magnetic stirrer at room temperature, the color changed from colorless to brownish yellow within 5 minutes (changed to 
dark reddish brown 15 minutes later). After 24 hours, no further color change was observed, signifying the stability of the synthesized nanoparticles. The results are shown in Table 1.

The appearance of the reddish brown color was only due to the reduction of $\mathrm{Ag}^{+}$, which confirms the formation of $\mathrm{Ag}$ nanoparticles as shown in Figure 1 (A and B).

\section{Characterization of AgNPs: UV-Vis spectrophotometeric analysis}

This color change is considered to be a standard indicator for synthesis of AgNPs. The UV-Vis spectrum of AgNPs synthesized by $R$. damascena is shown in Figure 2. The distinct peak observed at $415 \mathrm{~nm}$ corresponds to surface plasmon resonance of AgNPs.

The presence of the dark brown color and the peak at $415 \mathrm{~nm}$ implies the synthesis of AgNPs.

\section{FTIR analysis}

FTIR spectrum of the synthesized AgNPs and the leaf extract has been displayed in Figure 3. The FTIR spectrum of leaf extract (Figure 3) shows several absorption peaks at 3,399, $2,135,1,640,1,074,726$, and $407 \mathrm{~cm}^{-1}$. The intense broad line at $3,399 \mathrm{~cm}^{-1}$ is characteristic of the hydroxyl functional group in alcohols and phenolic compounds due to the stretching vibrations. Among all these, the peaks at 3,399, 2,135 , and $1,640 \mathrm{~cm}^{-1}$ appeared similarly in the spectrum of AgNPs (Figure 4). The bands at $2,135 \mathrm{~cm}^{-1}$ could be due to weak alkyne $\mathrm{C} \equiv \mathrm{C}$ stretching which is associated with lipid molecules in the leaf broth. The band at $1,640 \mathrm{~cm}^{-1}$ is due to amide II bond conjugated at $\mathrm{C}=\mathrm{O}$ from proteins. The bands at $1,375 \mathrm{~cm}^{-1}$ in AgNPs corresponded to $-\mathrm{C}-\mathrm{O}-$ stretching vibration. The weak bands appearing at 1,074 and 1,042 $\mathrm{cm}^{-1}$ in spectra of leaf extract and AgNPs, respectively, was due to $-\mathrm{C}-\mathrm{C}-$ stretches of lipids and sugars. The bands around 720,750 , and $693 \mathrm{~cm}^{-1}$ can be assigned to phenyl $(\mathrm{C}-\mathrm{H})$ stretch, respectively. The bands at 2,284, 1,381, 1,054, and $613 \mathrm{~cm}^{-1}$ disappeared completely from the spectrum of AgNPs.

Table I Color change during synthesis of nanoparticles

\begin{tabular}{|c|c|c|c|c|}
\hline $\begin{array}{l}\text { Serial } \\
\text { number }\end{array}$ & $\begin{array}{l}\text { Aqueous } \\
\text { AgNO }_{3} \\
\text { color }\end{array}$ & $\begin{array}{l}\text { Color } \\
\text { change in } \\
5 \text { minutes }\end{array}$ & $\begin{array}{l}\text { Color } \\
\text { change in } \\
\text { I } 5 \text { minutes }\end{array}$ & $\begin{array}{l}\text { Color } \\
\text { change after } \\
24 \text { hours }\end{array}$ \\
\hline I & $\begin{array}{l}\text { White } \\
\text { transparent }\end{array}$ & $\begin{array}{l}\text { Brownish } \\
\text { yellow }\end{array}$ & $\begin{array}{l}\text { Dark } \\
\text { reddish } \\
\text { brown }\end{array}$ & $\begin{array}{l}\text { No change still } \\
\text { dark reddish } \\
\text { brown }\end{array}$ \\
\hline
\end{tabular}

Abbreviation: $\mathrm{AgNO}_{3}$, silver nitrate.
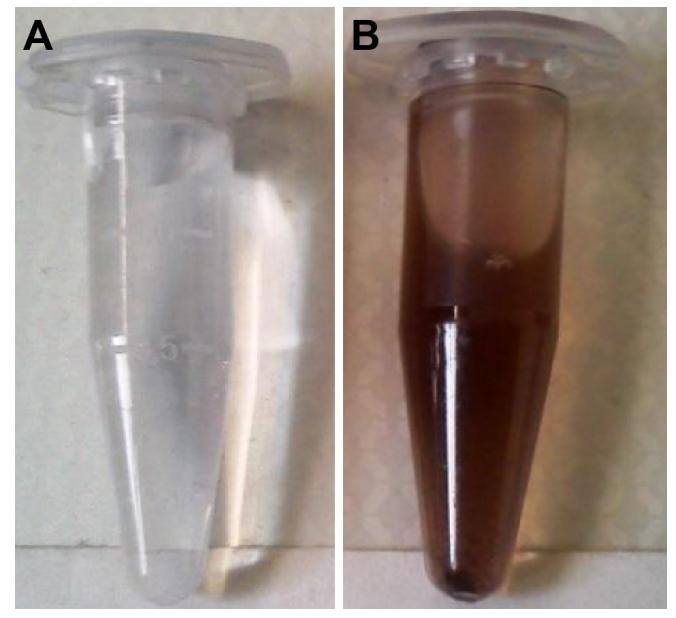

Figure I Synthesis of silver nanoparticles.

Notes: (A) $\mathrm{AgNO}_{3}$ solution; (B) synthesized silver nanoparticles exhibiting brown color.

Abbreviation: $\mathrm{AgNO}_{3}$, silver nitrate.

The dual role of the plant extract as a reducing as well as a capping agent and the presence of some functional groups was confirmed by FTIR analysis of AgNPs. These results suggested that the AgNPs have been synthesized due to the action of extract of the plant, $R$. damascena, which can act as a potentially good bioreductant for biosynthesis.

\section{TEM analysis}

TEM technique was used to visualize the size and shape of synthesized AgNPs through leaf extract of $R$. damascena. It is evident from Figure 5, that most of the synthesized particles were polydispersed, irregular in shape, and flowerlike. The average size of the individual nanoparticles was estimated $\sim 16 \mathrm{~nm}$, whereas polydispersed particles were in

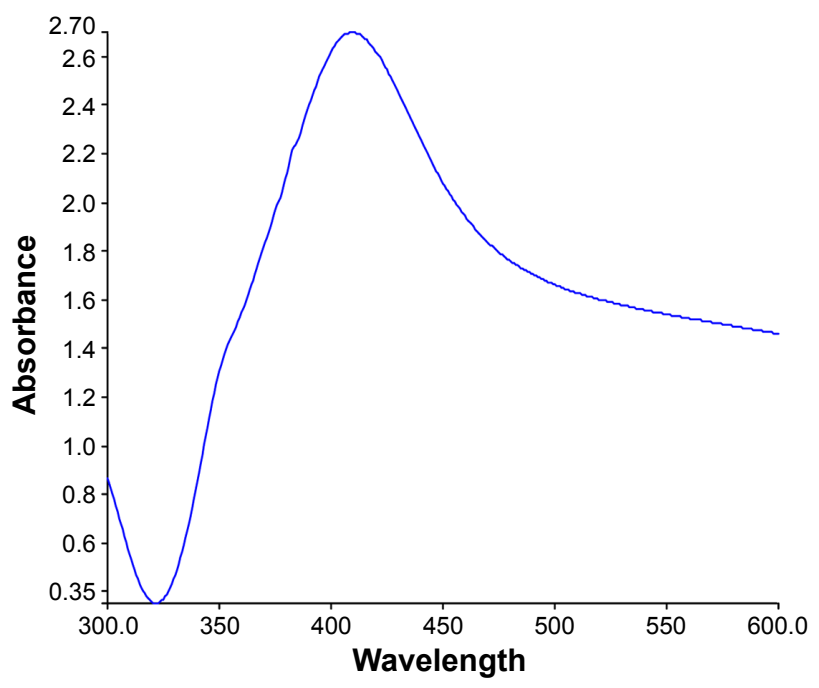

Figure 2 UV-Vis analysis of AgNPs.

Abbreviations: AgNPs, silver nanoparticles; UV-Vis, ultraviolet-visible. 


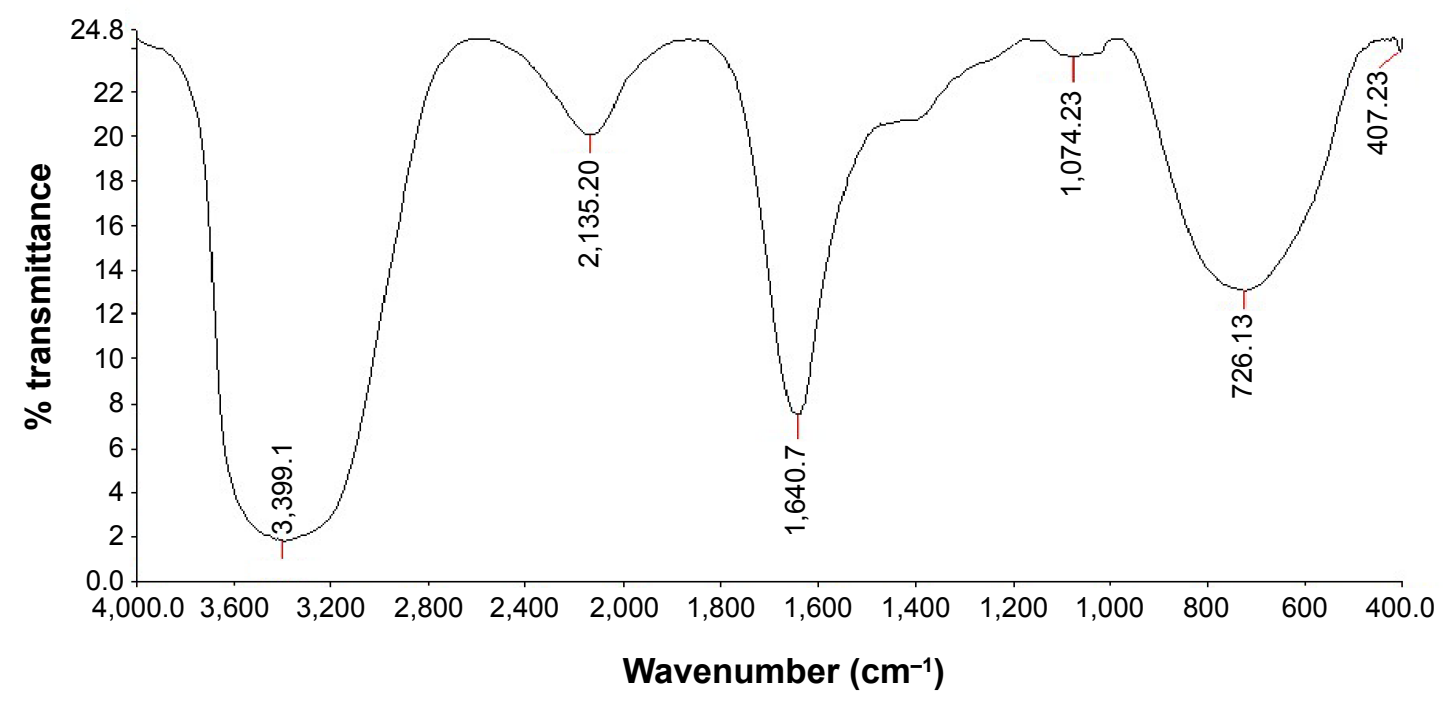

Figure 3 FTIR spectrum for Rosa damascena extract.

Abbreviation: FTIR, Fourier transform infrared spectroscopy.

the range of $60-80 \mathrm{~nm}$. The maximum size and minimum size of synthesized individual AgNP were found to be 24.6 and $11.6 \mathrm{~nm}$, respectively.

\section{DLS measurement analysis}

DLS measurement was performed to investigate the size and polydispersity of synthesized AgNPs. The hydrodynamic radii $\left(R_{\mathrm{h}}\right)$ of AgNPs were found to be in range of 30-100 nm (Figure 6). As evident by the intensity, the maximum nanoparticles were on average $60 \mathrm{~nm}$, with 50 and $80 \mathrm{~nm}$ being the next most prominent sizes. Since the TEM study showed that the average size of synthesized individual nanoparticles is $16 \mathrm{~nm}$, the increase in size can be attributed to polydispersion of nanoparticles. This study confirms that the particles synthesized are indeed under $100 \mathrm{~nm}$ and can be classified as nanoparticles.

\section{FESEM analysis}

The surface morphology of AgNPs was investigated using FESEM. The micrographs (Figure 7A and B) showed that synthesized AgNPs have rough surfaces and spherical and uneven irregular beads of different sizes. The result indicates the reduction process is being held at the surface. The rough surface may be advantageous for the immobilization of enzymes. As we can see from the micrograph, the nanoparticles were not in direct contact even within the aggregates, indicating stabilization of the nanoparticles by a capping agent.

\section{Effect of temperature on synthesis of AgNPs}

The effect of temperature on the rate of biosynthesis was examined by using different temperatures for the reaction,

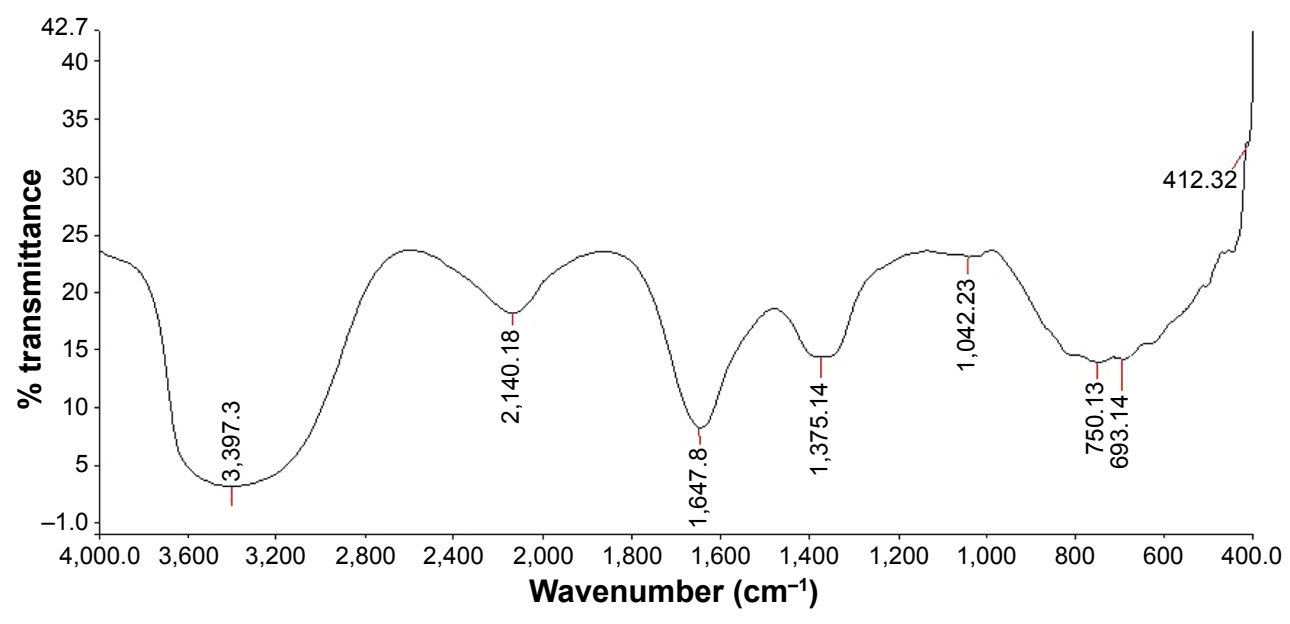

Figure 4 FTIR spectrum for the synthesized AgNPs.

Abbreviations: FTIR, Fourier transform infrared spectroscopy; AgNPs, silver nanoparticles. 


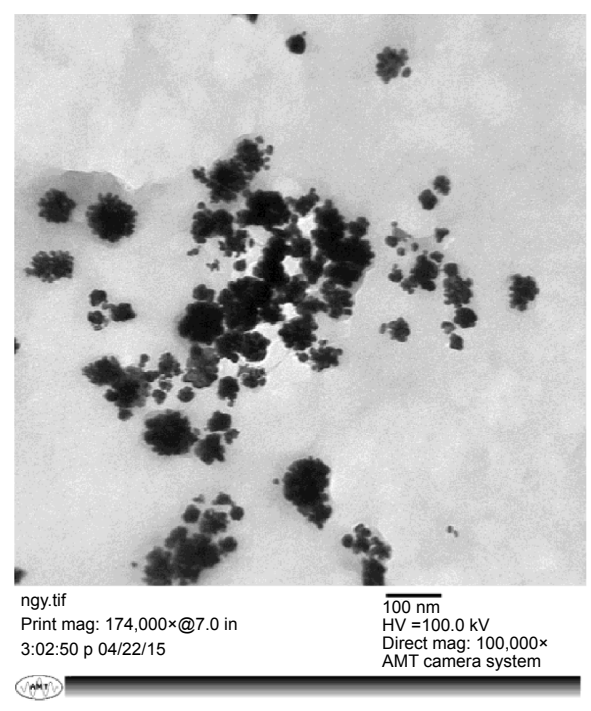

Figure 5 TEM micrograph shows the size of synthesized silver nanoparticles. Abbreviation: TEM, transmission electron microscopy.

from $10^{\circ} \mathrm{C}$ to $50^{\circ} \mathrm{C}$ for up to 6 hours, and was analyzed by measuring the absorbance at $420 \mathrm{~nm}$ using a UV-Vis double beam spectrophotometer. At lower temperatures, it was found that the rate of reaction was quite slow. From $10^{\circ} \mathrm{C}$ to $30^{\circ} \mathrm{C}$, the reaction rate did not increase significantly with increase in temperature, but as the temperature was elevated to $40^{\circ} \mathrm{C}$, a significant increase in the rate of reaction was observed. The reaction rate of synthesis of AgNPs was found to be quite similar at $40^{\circ} \mathrm{C}$ and $50^{\circ} \mathrm{C}$. The reduction of $\mathrm{Ag}$ ions reached its maximum after 5 hours, which could correspond to complete reduction of silver ions. The maximum reaction rate and reduction was obtained at $40^{\circ} \mathrm{C}$, and hence it was deemed as optimum temperature for reaction. Figure 8 shows the synthesis of AgNPs at different temperatures with respect to time.

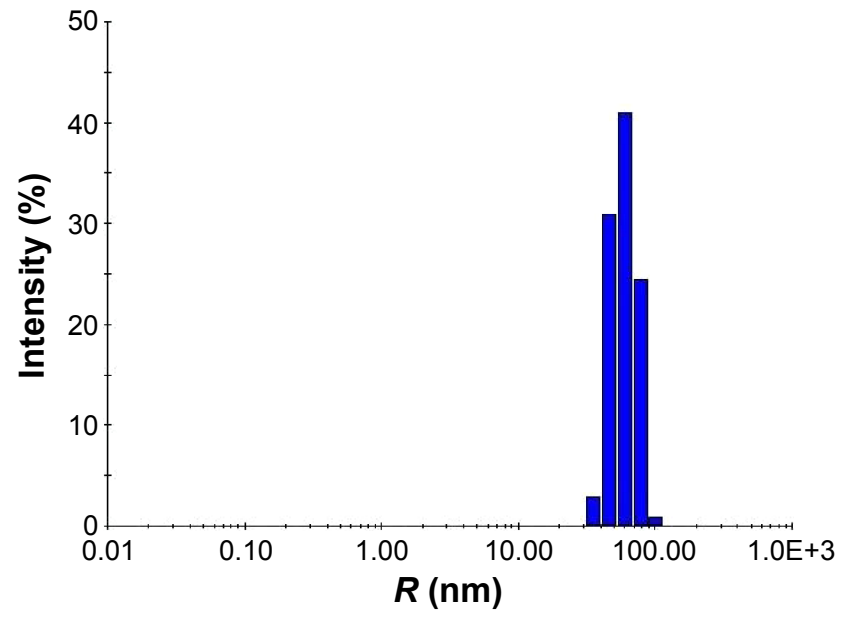

Figure 6 DLS analysis of synthesized nanoparticles. Abbreviation: DLS, dynamic light scattering.

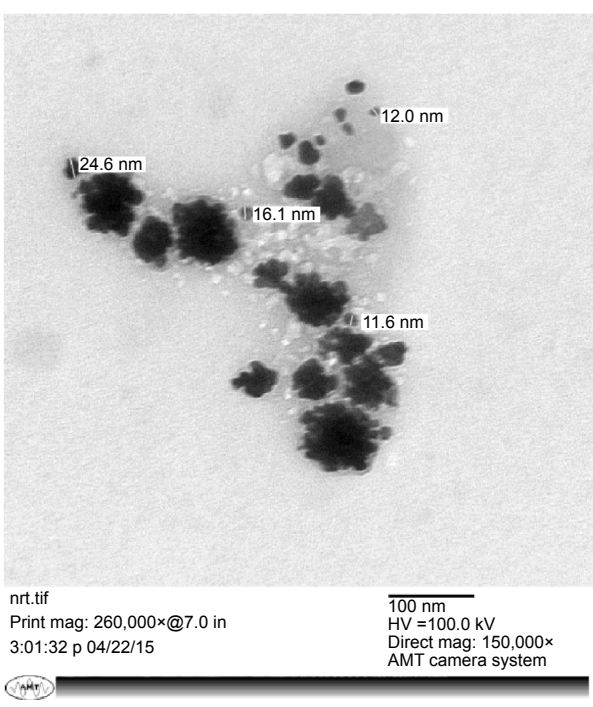

\section{Test for phenolic residues and bound phenol}

The role of phenolic compounds was confirmed by performing ferric ion reduction test. Addition of the ferric chloride solution to the $R$. damascena extract causes the color to change to bluish black and leads to precipitation later. This precipitation and color change indicates the presence of condensed tannins in the leaves extract. No color change was observed with the supernatant of leaf extract obtained after the synthesis of AgNPs after addition of ferric chloride solution (Figure 9). This test affirms that the phenolic compounds in the $R$. damascena extract were responsible for the reduction of $\mathrm{AgNO}_{3}$ to $\mathrm{AgNPs}$ and that no phenolic residues are present in the leaf extract after the synthesis, exemplifying that the phenol or phenolic compounds have been utilized during the synthesis.

\section{Antibacterial efficacy of synthesized nanoparticles}

The antibacterial activity of AgNPs against $E$. coli was found to be higher than that against $B$. cereus, which may be a consequence of the disparity in the cell wall constitution between Gram-positive and Gram-negative bacteria (Figure 10). The exact mechanism of such a reaction has not been elucidated yet. The plate with Gram-negative bacteria had clear zones of inhibition for penicillin and AgNPs, whereas no such zone was present in the Gram-positive bacterium plate. The leaf extract acting as control showed no zone of inhibition in either plate, indicating that the antibacterial activity of AgNPs is independent of the leaf extract used. The antibacterial 


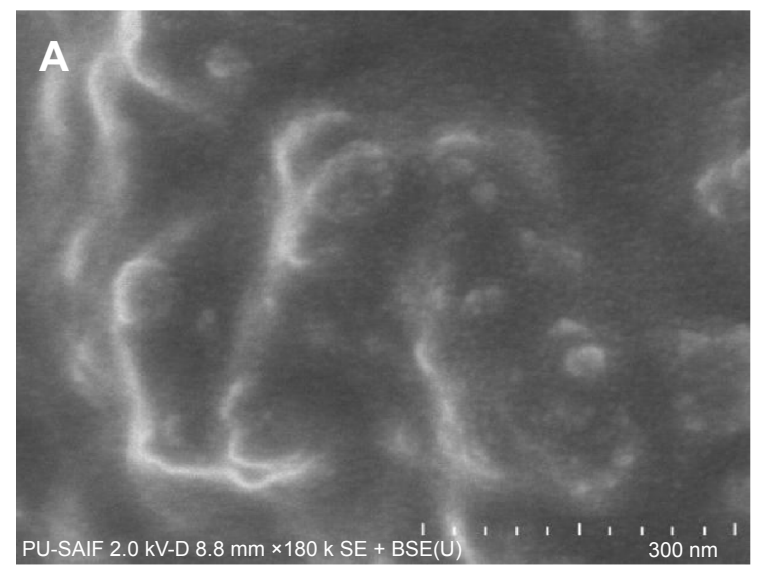

Figure 7 SEM imaging of AgNPs (A) at $300 \mathrm{~nm}$ scale; (B) at $500 \mathrm{~nm}$ scale. Abbreviations: SEM, scanning electron microscopy; AgNPs, silver nanoparticles.

activity was found to be lesser than penicillin, judging by the zone of inhibition, but the presence of antibacterial activity can be used in concomitance with other antimicrobial agents to increase their efficacy.

\section{Test for anti-inflammatory properties of AgNPs on rat model}

AgNPs were able to produce a significant anti-inflammatory action in the rat model. The effectiveness of the synthesized AgNPs was at its maximum for the 1st hour, judging by the decrease in paw volume between 30 minutes and 1 hour. By the 2-hour mark, the effectiveness started to reduce, but the effect was still significant. After the completion of 3rd hour, the effectiveness starts to tail off, but is still in the significant range. This action was compared to the action of the standard indomethacin, which was found to be quite significant even after 3 hours. The results have been presented graphically in Figure 11. These results show that even though AgNPs on their own are not as

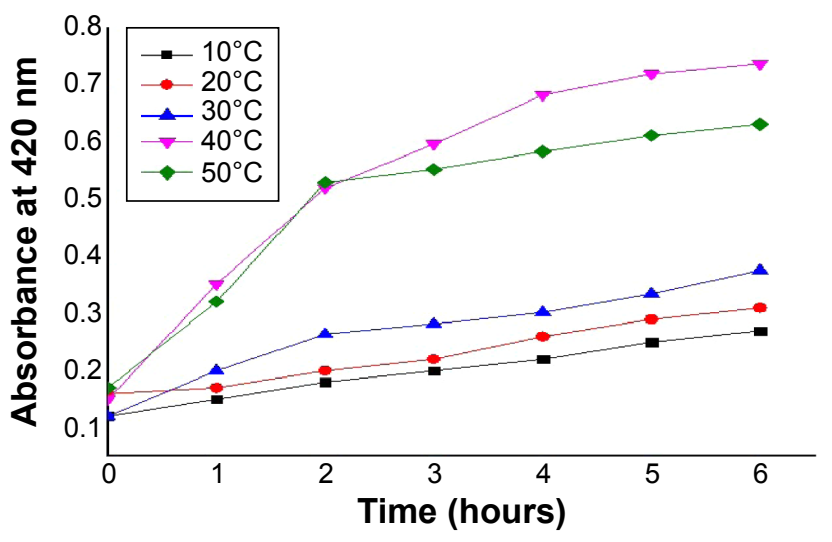

Figure 8 Effect of temperature on AgNPs synthesis. Abbreviation: AgNPs, silver nanoparticles.

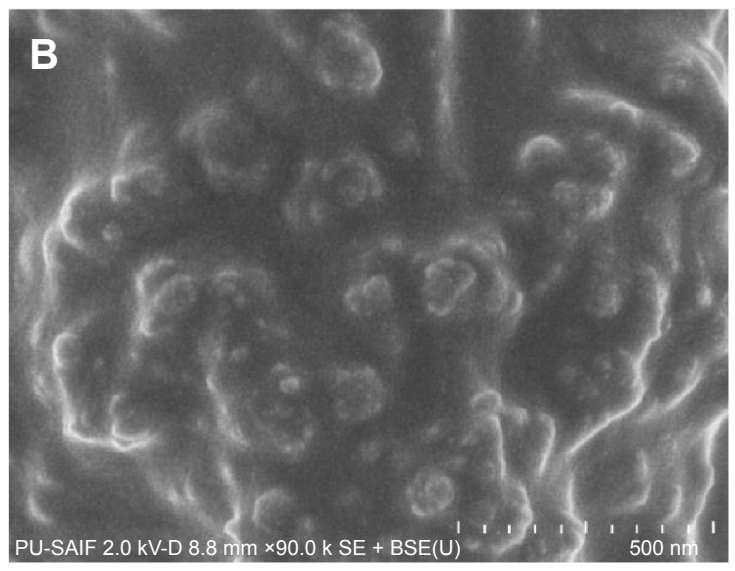

effective as the standard drugs for reducing the inflammation, it nevertheless presents us with an interesting option to be used in union with the standard drugs, to augment their effectiveness. These results are in concurrence with earlier studies which state that AgNPs do possess antiinflammatory properties. ${ }^{46,49}$ The data is presented in the form of Table 2. Results are expressed as mean \pm standard error of mean $(n=6)$ analyzed by one way ANOVA followed by Dunnett's test.

\section{Test for analgesic activity on rats}

Tail-flick test was performed on the part of the tail within $2 \mathrm{~cm}$ from root. Thermal stimulus typically pertains to the superficial surface of the skin, and the energy due to stimulus absorbed in the skin is intensified in the dermal/epidermal junction because of the location of nerve terminals; therefore, this particular assay method is particularly valuable in investigating the effect of analgesics. Analgesic activity was examined by digital analgesiometer. The decrease in the tail withdrawal time after application of AgNPs suggested that it might have some antianalgesic properties. The inhibition percentage was $16.74 \%$ as compared to $44.70 \%$ exhibited by pentazocine, which shows that even though AgNPs are not as effective as the standard drugs, they still exhibit an antianalgesic effect and can be used in conjunction with other standard antianalgesic agents to increase their efficacy. These results are in accordance with the previous studies which state that AgNPs do exhibit significant analgesic activities. ${ }^{50}$ The data has been presented in Table 3 and is represented graphically in Figure 12. Results are expressed as mean \pm standard error of mean $(n=6)$ analyzed by one way ANOVA followed by Dunnett's test. 

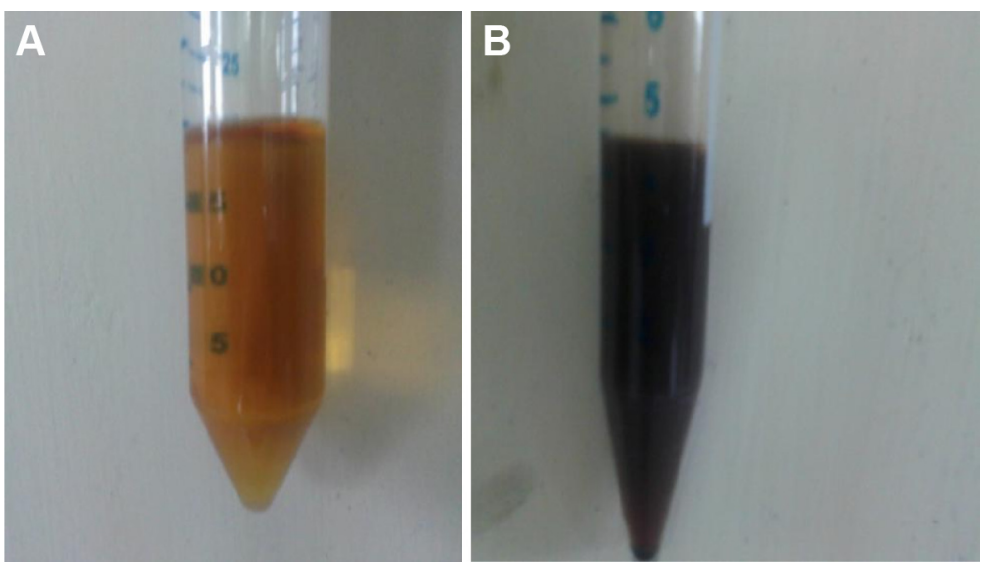

Figure 9 Ferric ion reduction test.

Notes: (A) Ferric chloride solution; (B) color change in Rosa damascena extract.
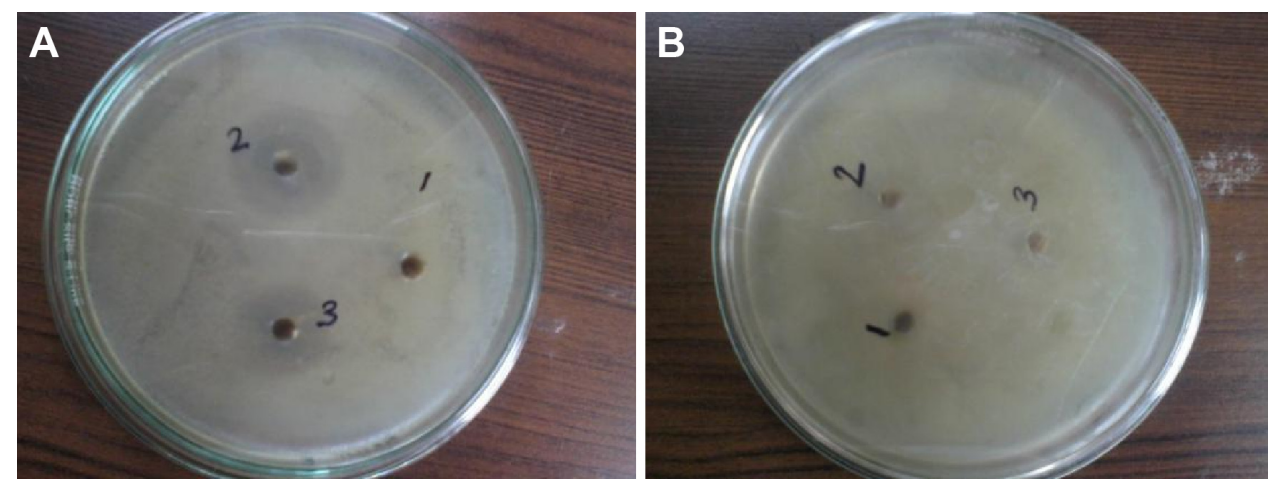

Figure 10 Antibacterial action of synthesized AgNPs.

Notes: (A) Against Escherichia coli; (B) against Bacillus cereus.

Abbreviation: AgNPs, silver nanoparticles.

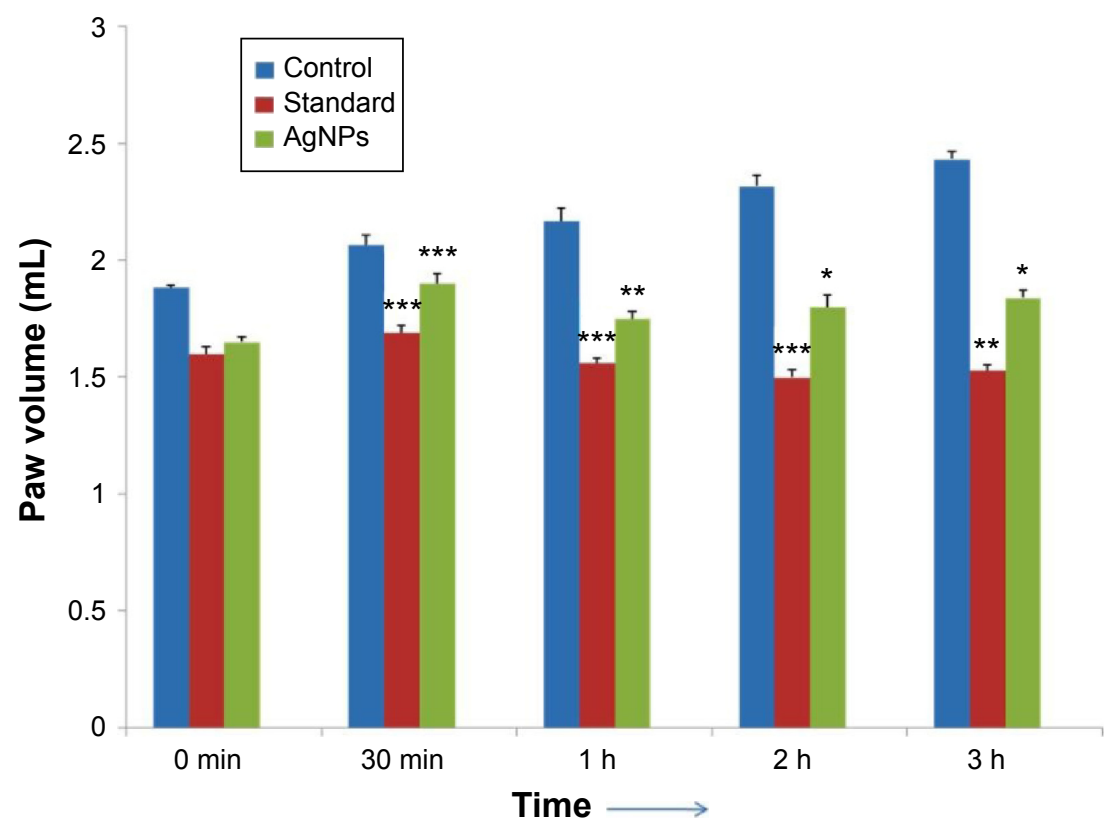

Figure I I Anti-inflammatory properties of AgNPs vs standard indomethacin.

Notes: $* P<0.05, * * P<0.01$, $* * * P<0.001$, when control group compared with other treated groups.

Abbreviations: AgNPs, silver nanoparticles; min, minute; h, hour. 
Table 2 Decrease in mean paw volume after administration of control, standard, and AgNPs with respect to time

\begin{tabular}{|c|c|c|c|c|c|c|}
\hline \multirow{2}{*}{$\begin{array}{l}\text { Serial } \\
\text { number }\end{array}$} & \multirow[t]{2}{*}{ Drugs (dose) } & \multicolumn{5}{|c|}{ Mean paw volume in $\mathrm{mL} \pm \mathrm{SEM}, \mathrm{n}=6$, and percentage edema inhibition } \\
\hline & & 0 minute & 30 minutes & I hour & 2 hours & 3 hours \\
\hline I & Control (I\% CMC) $(10 \mathrm{~mL} / \mathrm{kg})$ & $\mathrm{I} .88 \pm 0.0 \mathrm{I}$ & $2.06 \pm 0.04$ & $2.16 \pm 0.05$ & $2.31 \pm 0.04$ & $2.43 \pm 0.06$ \\
\hline 2 & Standard indomethacin $(10 \mathrm{mg} / \mathrm{kg})$ & $1.6 \pm 0.08$ & $1.69 \pm 0.03 *$ & $1.56 \pm 0.04 *$ & $1.5 \pm 0.02 *$ & $1.53 \pm 0.06 * *$ \\
\hline 3 & AgNPs & $1.65 \pm 0.02$ & $1.9 \pm 0.04 *$ & $1.75 \pm 0.06$ ** & $1.8 \pm 0.08 * * *$ & $1.84 \pm 0.08 * * *$ \\
\hline
\end{tabular}

Notes: $* P<0.001, * * P<0.01$, $* * * P<0.05$, when control group compared with other treated groups.

Abbreviations: AgNPs, silver nanoparticles; SEM, standard error of the mean; CMC, carboxymethyl cellulose.

\section{Conclusion}

In summary, biological reduction of AgNPs was achieved using $R$. damascena leaf extract without any use of chemicals, making this technique for synthesis invaluable for the environmental concerns. The synthesis was accomplished under high temperature with vigorous stirring and the created nanoparticles were characterized using several techniques, viz, UV-Vis spectroscopy, FTIR, DLS, TEM, and FESEM. The individual nanoparticles were found to be of $16 \mathrm{~nm}$ in size, whereas polydispersed nanoparticles were in the range of $60-80 \mathrm{~nm}$ on average, having rugged surface morphology and possessing a flower-like structure. The reducing properties of leaf extract were attributed to phenolic compounds present in the extract, as evident by the test conducted for presence of phenolic compounds in the extract before and after synthesis. The leaves were sterilized before the extraction, for the removal of contaminants inhabiting the surface, and this may well be the first study to do so. Although the green synthesis is far more economical as compared to the other technologies for synthesis of nanoparticles, the commercial viability of the process for the synthesis of nanoparticles using these swiftly obtainable plant extracts must be assessed before employing them on a large scale.

The synthesized AgNPs exhibited a strong antibacterial activity against Gram-negative bacterium E. coli, but not against $B$. cereus, which is a Gram-positive bacterium. This difference in action could be ascribed to the difference in cell wall composition, but the exact mechanism of antibacterial action of AgNPs has not been explicated yet. The anti-inflammatory and analgesic properties of the nanoparticles were tested on Wistar rats. AgNPs were found to possess anti-inflammatory as well as analgesic properties, although the activity was quite less as compared to the standards in both the cases. The anti-inflammatory activity was found to be at its maximum after 1 hour of AgNP administration and was significant even after 3 hours, but was a fraction of the activity demonstrated by the standard indomethacin. The analgesic activity, calculated using percentage inhibition, showed that AgNPs reduced the time between the tail flicks by $16.74 \%$ as compared to $44.70 \%$ achieved by the standard, pentazocine, which illustrated that analgesic action of AgNPs is not as potent as the standard drugs, but the presence of small quantities of antibacterial, anti-inflammatory, and analgesic activity can be used in conjunction with the standard drugs to enhance their efficacy.

\section{Acknowledgments}

The authors wish to acknowledge Prof RM Dubey, Vice Chancellor of the IFTM University, Moradabad; Prof AK Ghosh, Director, School of Biotechnology; Prof Sanjay Mishra, Dean, School of Biotechnology; and Mr Phool Chand, Assistant Professor, School of Pharmaceutical Sciences, IFTM University, Moradabad for providing all the necessary facilities, support, and encouragement to the authors to complete this task. We would also like to extend our gratitude to the SAIF Chandigarh, India for characterization of samples.

Table 3 Protective effect of AgNPs on tail withdrawal reflexes in rats determined by tail-flick method

\begin{tabular}{lllll}
\hline $\begin{array}{l}\text { Serial } \\
\text { number }\end{array}$ & Drugs (dose) & $\begin{array}{l}\text { Before treatment } \\
\text { (mean } \pm \text { SEM) }\end{array}$ & $\begin{array}{l}\text { After treatment } \\
\text { (mean } \pm \text { SEM) }\end{array}$ & $\begin{array}{l}\text { Percentage } \\
\text { inhibition (\%) }\end{array}$ \\
\hline 1 & Control & $6.03 \pm 0.176$ & $5.9 \pm 0.106$ & 0.00 \\
2 & Pentazocine $(30 \mathrm{mg} / \mathrm{kg})$ & $5.86 \pm 0.149$ & $8.48 \pm 0.382 *$ & 44.70 \\
3 & AgNPs $(0.025 \mathrm{mg} / \mathrm{mL})$ & $6.15 \pm 0.178$ & $7.18 \pm 0.242^{* *}$ & 16.74 \\
\hline
\end{tabular}

Notes: $* P<0.001$, ${ }^{* *} P<0.05$, when control group compared with other treated groups. Abbreviations: AgNPs, silver nanoparticles; SEM, standard error of the mean. 


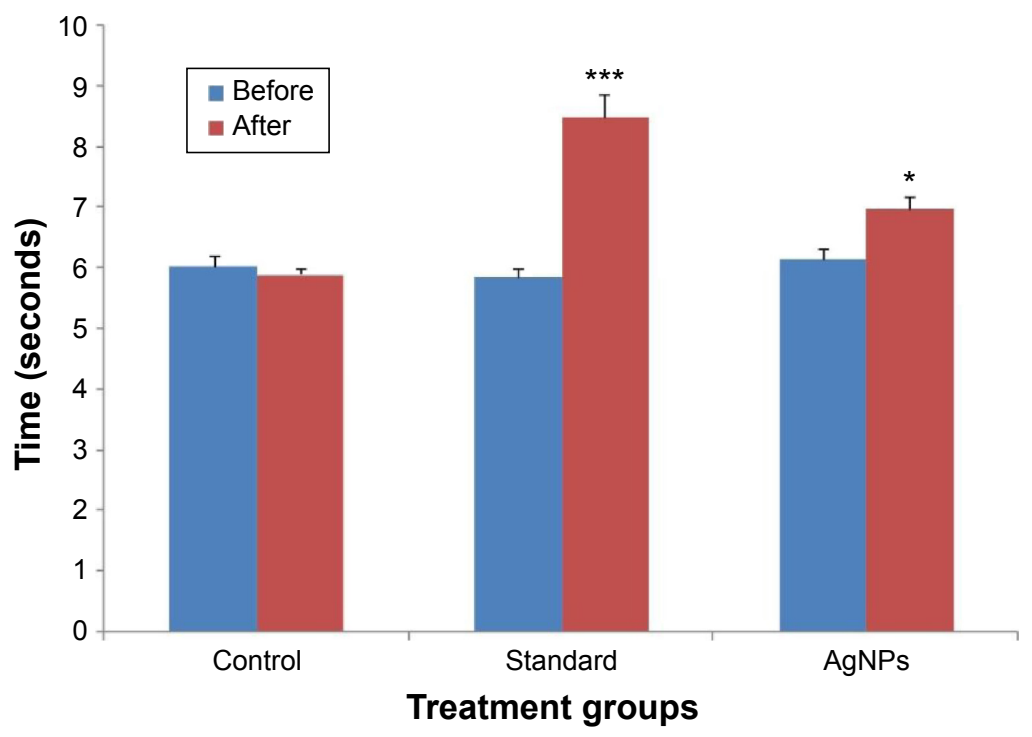

Figure 12 Protective effect of AgNPs on tail withdrawal reflexes induced by tail-flick method in rat. Notes: $* P<0.05, * * * P<0.00$ I, when control group compared with other treated groups.

Abbreviation: AgNPs, silver nanoparticles.

\section{Disclosure}

The authors report no conflicts of interest in this work.

\section{References}

1. Ishijima A, Toshio Y. Single molecule nanobioscience. Trends Biochem Sci. 2001;26(7):438-444.

2. Yanagida T. Single molecule nano-bioscience. In: TRANSDUCERS, 12th International Conference on Solid-State Sensors, Actuators and Microsystems. Boston, MA: IEEE; 2003.

3. Ahmad N, Kumar MS. Nanoparticles: study of preparation \& its toxicity effects on living systems. Bionano Front. 2011;4(1):1-5.

4. Huang J, Li Q, Daohua S, et al. Biosynthesis of silver and gold nanoparticles by novel sundried Cinnamomum camphora leaf. Nanotechnology. 2007;18(10):105104.

5. Lukman AI, Gong B, Marjo CE, Roessner U, Harris AT. Facile synthesis, stabilization, and anti-bacterial performance of discrete $\mathrm{Ag}$ nanoparticles using Medicago sativa seed exudates. J Colloid Interface Sci. 2011;353(2):433-444.

6. Armendariz V, Herrera I, Jose-yacaman M, Troiani H, Santiago P, Gardea-Torresdey JL. Size controlled gold nanoparticle formation by Avena sativa biomass: use of plants in nanobiotechnology. J Nanopart Res. 2004;6(4):377-382.

7. Tripathy A, Raichur AM, Chandrasekaran N, Prathna TC, Mukherjee A. Process variables in biomimetic synthesis of silver nanoparticles by aqueous extract of Azadirachta indica (Neem) leaves. J Nanopart Res. 2010;12(1):237-246.

8. Elumalai K, Velmurugan S, Ravi S, Kathiravan V, Ashokkumar S. Facile, eco-friendly and template free photosynthesis of cauliflower like $\mathrm{ZnO}$ nanoparticles using leaf extract of Tamarindus indica (L.) and its biological evolution of antibacterial and antifungal activities. Spectrochim Acta A Mol Biomol Spectrosc. 2015;136 Pt B: 1052-1057.

9. Balaprasad A, Damle C, Ahmad A, Sastry M. Biosynthesis of gold and silver nanoparticles using Emblica officinalis fruit extract, their phase transfer and transmetallation in an organic solution. J Nanosci Nanotechnol. 2005;5(10):1665-1671.

10. Chandran SP, Chaudhary M, Pasricha R, Ahmad A, Sastry M. Synthesis of gold nanotriangles and silver nanoparticles using Aloe vera plant extract. Biotechnol Prog. 2006;22(2):577-583.
11. Zhang Y, Yang D, Kong Y, Wang X, Pandoli O, Gao G. Synergetic antibacterial effects of silver nanoparticles @ Aloe vera prepared via a green method. Nano Biomed Eng. 2010;2(4):252-257.

12. Sathyavathi R, Krishna MB, Rao SV, Saritha R, Rao DN. Biosynthesis of silver nanoparticles using Coriandrum sativum leaf extract and their application in nonlinear optics. Adv Sci Lett. 2010;3(2):138-143.

13. Rao SV. Picosecond nonlinear optical studies of gold nanoparticles synthesised using coriander leaves (Coriandrum sativum). J Mod Opt. 2011;58(12):1024-1029.

14. Mude N, Ingle A, Gade A, Rai M. Synthesis of silver nanoparticles using callus extract of Carica papaya - a first report. J Plant Biochem Biotechnol. 2009;18(1):83-86.

15. Jain D, Daima HK, Kachhwaha S, Kothari SL. Synthesis of plantmediated silver nanoparticles using papaya fruit extract and evaluation of their anti-microbial activities. Dig J Nanomater Biostruct. 2009;4(3): 557-563.

16. Parashar V, Parashar R, Sharma B, Pandey AC. Parthenium leaf extract mediated synthesis of silver nanoparticles: a novel approach towards weed utilization. Dig J Nanomater Biostruct. 2009;4(1):45-50.

17. Rajiv P, Rajeshwari S, Venckatesh R. Bio-fabrication of zinc oxide nanoparticles using leaf extract of Parthenium hysterophorus L. and its size-dependent antifungal activity against plant fungal pathogens. Spectrochim Acta A Mol Biomol Spectrosc. 2013;112:384-387.

18. Inbakandan D, Venkatesan R, Khan SA. Biosynthesis of gold nanoparticles utilizing marine sponge Acanthella elongata (Dendy, 1905). Colloids Surf B Biointerfaces. 2010;81(2):634-639.

19. Inbakandan D, Sivaleela G, Peter DM, Kiurbagaran R, Venkatesan R, Khan SA. Marine sponge extract assisted biosynthesis of silver nanoparticles. Mater Lett. 2012;87:66-68.

20. Nabikhan A, Kandasamy K, Raj A, Alikunhi NM. Synthesis of antimicrobial silver nanoparticles by callus and leaf extracts from saltmarsh plant, Sesuvium portulacastrum L. Colloids Surf B Biointerfaces. 2010; 79(2):488-493.

21. Arokiyaraj S, Mariadhas VA, Savariar V, et al. Rapid green synthesis of silver nanoparticles from Chrysanthemum indicum $L$ and its antibacterial and cytotoxic effects: an in vitro study. Int J Nanomedicine. 2014; 9:379

22. Mehmood A, Ghulam M, Tariq MB, Muhammad R, Rehana K. Antibacterial efficacy of silver nanoparticles synthesized by a green method using bark extract of Melia azedarach L. J Pharm Innov. 2014;9(3):238-245. 
23. Vidhu VK, Daizy P. Spectroscopic, microscopic and catalytic properties of silver nanoparticles synthesized using Saraca indica flower. Spectrochim Acta A Mol Biomol Spectrosc. 2014;117:102-108.

24. Jeeva K, Thiyagarajan M, Elangovan V, Geetha N, Venkatachalam P. Caesalpinia coriaria leaf extracts mediated biosynthesis of metallic silver nanoparticles and their antibacterial activity against clinically isolated pathogens. Ind Crops Prod. 2014;52:714-720.

25. Zargar M, Kamyar S, Gholam RN, Farah F. Plant mediated green biosynthesis of silver nanoparticles using Vitex negundo L. extract. J Ind Eng Chem. 2014;20(6):4169-4175.

26. Venu R, Ramulu TS, Anandakumar S, Rani VS, Kim CG. Bio-directed synthesis of platinum nanoparticles using aqueous honey solutions and their catalytic applications. Colloids Surf A Physicochem Eng Asp. 2011; 384(1):733-738.

27. Daizy P. Honey mediated green synthesis of silver nanoparticles. Spectrochim Acta A Mol Biomol Spectrosc. 2010;75(3):1078-1081.

28. Mittal AK, Chisti Y, Banerjee UC. Synthesis of metallic nanoparticles using plant extracts. Biotechnol Adv. 2013;31(2):346-356.

29. Kumar V, Yadav SK. Plant-mediated synthesis of silver and gold nanoparticles and their applications. J Chem Technol Biotechnol. 2009;84(2): 151-157.

30. Salata OV. Applications of nanoparticles in biology and medicine. J Nanobiotechnol. 2004;2(1):3.

31. Singh R, Nalwa HS. Medical applications of nanoparticles in biological imaging, cell labeling, antimicrobial agents, and anticancer nanodrugs. J Biomed Nanotechnol. 2011;7(4):489-503.

32. Rai M, Yadav A, Gade A. Silver nanoparticles as a new generation of antimicrobials. Biotechnol Adv. 2009;27(1):76-83.

33. Morones JR, Elechiguerra JL, Camacho A, et al. The bactericidal effect of silver nanoparticles. Nanotechnology. 2005;16(10):2346.

34. Orza A, Olga S, Ciprian T, et al. Reversing chemoresistance of malignant glioma stem cells using gold nanoparticles. Int J Nanomedicine. 2013; 8:689.

35. Tomuleasa C, Olga S, Orza A, et al. Gold nanoparticles conjugated with cisplatin/doxorubicin/capecitabine lower the chemoresistance of hepatocellular carcinoma-derived cancer cells. J Gastrointestin Liver Dis. 2012;21(2):187-196.

36. Orza A, Daniel C, Alexandru B. Nanomaterials for targeted drug delivery to cancer stem cells. Drug Metab Rev. 2014;46(2):191-206.

37. Poirier M, Jean-Christophe S, Francis A, Denis G. Interaction between silver nanoparticles of $20 \mathrm{~nm}$ (AgNP20) and human neutrophils: induction of apoptosis and inhibition of de novo protein synthesis by AgNP20 aggregates. J Appl Toxicol. 2014;34(4):404-412.
38. Lok CN, Taotao Z, Zhang JJ, Iris WSL, Che CM. Controlled-release systems for metal-based nanomedicine: encapsulated/self-assembled nanoparticles of anticancer gold (iii)/platinum (ii) complexes and antimicrobial silver nanoparticles. Adv Mater. 2014;26(31):5550-5557.

39. Agnihotri S, Mukherji S, Mukherji S. Size-controlled silver nanoparticles synthesized over the range 5-100 nm using the same protocol and their antibacterial efficacy. RSC Adv. 2014;4(8):3974-3983.

40. Liu CY, Hu JM. Hydrogen peroxide biosensor based on the direct electrochemistry of myoglobin immobilized on silver nanoparticles doped carbon nanotubes film. Biosens Bioelectron. 2009;24(7):2149-2154.

41. Klaus-Joerger T, Joerger R, Olsson E, Granqvist CG. Bacteria as workers in the living factory: metal-accumulating bacteria and their potential for materials science. Trends Biotechnol. 2001;19(1):15-20.

42. Schrand AM, Braydich-Stolle LK, Schlager JJ, Dai L, Hussain SM. Can silver nanoparticles be useful as potential biological labels? Nanotechnology. 2008;19(23):235104.

43. Ahmad N, Kavya S, Srivastava M, and Dutta R. Novel rapid biological approach for synthesis of silver nanoparticles and its characterization. Int J Pharmacol. 2014;1(1):28-31.

44. Rao JK, Paria S. Green synthesis of silver nanoparticles from aqueous Aeglemarmelos leaf extract. Mater Res Bull. 2013;48(2):628-634.

45. Patil CR, Gadekar AR, Patel PN, Rambhade A, Surana SJ, Gaushal MH. Dual effect of Toxicodendron pubescens on Carageenan induced paw edema in rats. Homeopathy. 2009;98:88-91.

46. Moldovan DL, Vulcu A, Olenic L, et al. Green synthesis, characterization and anti-inflammatory activity of silver nanoparticles using European black elderberry fruits extract. Colloids Surf B Biointerfaces. 2014;122:767-777.

47. Vazquez B, Avila G, Segura D, Escalante B. Anti-inflammatory activity of extracts from Aloe vera gel. J Ethnopharmacol. 1996;55(1):69-75.

48. D'Amour FE, Smith DL. A method for determining loss of pain sensation. J Pharmacol Exp Ther. 1941;72(1):74-79.

49. Wong KK, Cheung SO, Huang L, et al. Further evidence of the antiinflammatory effects of silver nanoparticles. Chem Med Chem. 2009; 4(7):1129-1135.

50. Garg S, Chandra A, Mazumder A, Mazumder R. Analgesic potential of hydrogels of silver nanoparticles using aqueous extract of Saraca indica bark. Int J Pharm Sci Res. 2014;5(1):240.
International Journal of Nanomedicine

\section{Publish your work in this journal}

The International Journal of Nanomedicine is an international, peerreviewed journal focusing on the application of nanotechnology in diagnostics, therapeutics, and drug delivery systems throughout the biomedical field. This journal is indexed on PubMed Central, MedLine, CAS, SciSearch ${ }^{\circledR}$, Current Contents ${ }^{\circledR} /$ Clinical Medicine,

\section{Dovepress}

Journal Citation Reports/Science Edition, EMBase, Scopus and the Elsevier Bibliographic databases. The manuscript management system is completely online and includes a very quick and fair peer-review system, which is all easy to use. Visit http://www.dovepress.com/ testimonials.php to read real quotes from published authors. 